\title{
Exercise radionuclide ventriculography in children: normal values for exercise variables and right and left ventricular function
}

\author{
MARK D PARRISH, * ROBERT J BOUCEK JR, * JUDY BURGER, * \\ MICHAEL F ARTMAN, C LEON PARTAIN, $\dagger$ THOMAS P GRAHAM JR
}

From the Departments of ${ }^{\star}$ Pediatrics and $\nmid$ Radiology, Vanderbilt Medical Center, Nashville, Tennessee, USA

SUMMARY Thirty two children (aged 5-19 years) with no clinical evidence of significant cardiovascular disease undertook continuous staged supine exercise on a bicycle ergometer. Multigated radionuclide ventriculography was performed at rest and during each exercise stage. Exercise duration and total workload both increased with age. Aerobic work correlated better with age than did total work. In most children the ejection fraction for both ventricles increased by at least $5 \%$ with exercise. Right ventricular ejection fraction did not decrease with exercise in any subject but left ventricular ejection fraction decreased by $2 \%$ and $9 \%$ in two. The response of end diastolic volume to exercise was variable, but there was a consistent decrease in mean (SD) end systolic volume of the left $(29(22) \%$ ) and right $(30(19) \%$ ) ventricles. Cardiac index (mean (SD)) increased by $234(65) \%$ with exercise. The left ventricular:right ventricular end diastolic volume ratio (mean (SD)) at rest was $1 \cdot 26(0 \cdot 26)$.

It is concluded that exercise radionuclide ventriculography is an excellent technique for a combined assessment of exercise capacity and an evaluation of ventricular size and performance in children. These values for supine bicycle exercise in children without significant cardiovascular disease will be useful for future comparisons with other groups.

\begin{abstract}
Abnormalities of ventricular performance have been reported in children with diverse types of heart disease. $^{1-3}$ In several studies radionuclide ventriculography and exercise stress testing were used to assess such children. ${ }^{4-6}$ Most of these studies, however, have compared results from "abnormal" children with published data on normal adults. No data are available on the results of exercise radionuclide ventriculography in normal children, nor are data available on normal workloads, heart rate, and blood pressure response to supine bicycle exercise with a 4 minute per stage graded exercise protocol. We report the results of radionuclide ventriculography in 32 children who undertook supine exercise on a bicycle ergometer.
\end{abstract}

Requests for reprints to Dr Mark Parrish, Pediatrics Department, University of Texas Health Science Center at Dallas, 5323 Harry Hines Boulevard, Dallas, Texas 75235, USA.

Accepted for publication 7 May 1985

\section{Patients and methods}

\section{STUDY GROUP}

Between June 1980 and June 1983 we performed radionuclide ventriculography in 220 children. All had been referred for investigation for clinical reasons, and informed consent was obtained from each patient and their parents (institutional review committee approval, July 1982). Patients were eligible for inclusion if they had undergone an exercise radionuclide ventriculogram and they had no clinical evidence of structural heart disease, cardiac dysfunction, or congestive heart failure; were taking no medications; had no history of exercise intolerance; and had a normal baseline electrocardiogram, chest $x$ ray film, and echocardiogram. Thirty two of our 220 patients met these criteria. These 32 patients ranged in age from 5 to 19 years (mean (SD) $12 \cdot 4(3.6)$ years). Their weights ranged from 15 to 60 $\mathrm{kg}$ (mean (SD) $44 \cdot 3(17) \mathrm{kg}$ ). 
Ethical considerations prevent the recruitment of healthy children solely for the purposes of a radionuclide study. The diagnoses with which our 32 patients were referred were as follows; arrhythmias (extrasystoles or paroxysmal atrial arrhythmias) 13 patients; chest pain, seven patients; postoperative state, seven patients (six patients had had atrial septal defect repair and one patient had had repair of a partial anomalous pulmonary venous drainage); pectus excavatum, three patients; hyperlipidaemia, one patient; and normal heart, one patient. All postoperative patients had been operated on before the aged of 6 and were studied at least a year after operation. All patients (including those with a history of arrhythmias) were in normal sinus rhythm at the time of radionuclide study and did not have a history of chronic or incessant tachycardia. There was therefore no clinical reason to suspect any abnormality of ventricular function in these children.

Initially, results for the postoperative patients were examined separately and compared with the remaining patients. Since no significant differences were found all patients were subsequently grouped and analysed together.

\section{EXERCISE PROTOCOL}

The patients performed supine exercise on a bicycle ergometer and followed a continuous staged protocol similar to that described by Godfrey. ${ }^{7}$ Exercise was performed in 4 minute stages with an increase in workload at each stage up to the point of maximum voluntary patient effort. Stages lasting 4 minutes rather than 3 minute stages were chosen because the longer time allows us to obtain better quality radionuclide images. The workload was set at 200 $\mathrm{kpm} / \mathrm{min}(33.4 \mathrm{~W})$ for stage 1 , and increased by 200 $\mathrm{kpm} / \mathrm{min}(33.4 \mathrm{~W})$ for each subsequent stage. Pedal speed was maintained at between 60 and $80 \mathrm{rpm}$ for the duration of the exercise. In all children the rea- son for stopping exercise was leg fatigue. Three electrocardiographic leads were monitored continously throughout exercise (modified Frank system). We used an automated device to measure blood pressure in the arm every 2 minutes. This device uses acoustic transduction with electrocardiographic gating and signal filtering and has been validated for use in children during exercise. ${ }^{8}$ In eight children, free flowing venous blood samples for the determination of lactic acid were obtained before exercise and 2 mintues after exercise had ceased. In another seven children free flowing venous blood was obtained from an indwelling antecubital cannula every minute during exercise and for 5 minutes after exercise to determine the onset of metabolic acidosis (lactic acidaemia).

\section{RADIONUCLIDE STUDIES}

Multiple gated equilibrium radionuclide studies were performed with the subject in the supine position at rest and during the final 3 minutes of each exercise stage. We have already described and validated our data acquisition and analysis techniques. ${ }^{9-11}$ All studies were analysed to obtain right and left ventricular ejection fractions at rest and during peak exercise. In addition, we used a geometric formula to calculate left ventricular volumes at rest and with exercise. From these volumes and the ejection fraction we estimated the cardiac index at rest and during peak exercise. Using the regional blood counts, we also calculated a left ventricular to right ventricular volume ratio.

We required at least 1 minute of data acquisition during exercise to accumulate adequate radionuclide data. Eleven children exercised for less than 2 minutes (mean (SD) 1.0(0.4) minutes) of their final exercise stage. Thus for these children we used the preceding radionuclide image (obtained during the stage just before maximum exercise) to calculate peak exercise performance indices. The remaining

Table 1 Exercise performance in children aged 5-9 years (group 1), 10-14 years (group 2), and 15-19 years (group 3)

\begin{tabular}{|c|c|c|c|}
\hline & 1 & 2 & 3 \\
\hline $\begin{array}{l}\text { No patients } \\
\text { Age (yr) } \\
\text { Heart rate (beats/min) } \\
\text { Change in systolic blood pressure }(\mathrm{mm} \mathrm{Hg})\end{array}$ & $\begin{array}{l}7 \\
7 \cdot 3(1 \cdot 1) \\
80(15) \\
40(28)\end{array}$ & $\begin{array}{l}17 \\
12 \cdot 4(1 \cdot 5)^{\star} \\
86(20) \\
44(16)\end{array}$ & $\begin{array}{l}8 \\
16 \cdot 9(1 \cdot 3)^{\star} \dagger \\
111(24)^{\star} \dagger \\
61(25)\end{array}$ \\
\hline $\begin{array}{l}\text { Exercise time (min): } \\
\text { Boys } \\
\text { Girls } \\
\text { Combined }\end{array}$ & $\begin{array}{l}8 \cdot 6(1 \cdot 1) \\
7(0 \cdot 5) \\
7 \cdot 9(1 \cdot 2)\end{array}$ & $\begin{array}{l}11 \cdot 6(2 \cdot 3)^{\star} \\
11 \cdot 3(2 \cdot 9)^{\star} \\
11 \cdot 5(2 \cdot 4)^{\star}\end{array}$ & $\begin{array}{l}17 \cdot 5(3 \cdot 2)^{\star}+t \\
12(2 \cdot 8)^{\star} \\
16 \cdot 1(3 \cdot 8)^{\star} \dagger\end{array}$ \\
\hline $\begin{array}{l}\text { Total work }\left(\mathrm{kpm} / \mathrm{m}^{2}\right) \text { : } \\
\text { Boys } \\
\text { Girls } \\
\text { Combined }\end{array}$ & $\begin{array}{l}2943(478) \\
2157(224) \\
2606(555)\end{array}$ & $\begin{array}{l}3546(901) \\
3458(1489)^{\star} \\
3515(1096)\end{array}$ & $\begin{array}{l}5846(166)^{\star} \dagger \ddagger \\
3444(932) \\
5247(1829)^{\star} \dagger\end{array}$ \\
\hline
\end{tabular}

*Significantly different from group $1, \mathrm{p}<0.05$.

$\dagger$ Significantly different from group $2, \mathrm{p}<0.05$.

$¥$ \$oys significantly different from girls: $\mathrm{p}<0.05$.

Conversion: traditional units to $S \mathrm{I}-1 \mathrm{kpm} / \mathrm{m}^{2}=9.807 \mathrm{~J} / \mathrm{m}^{2}$. 

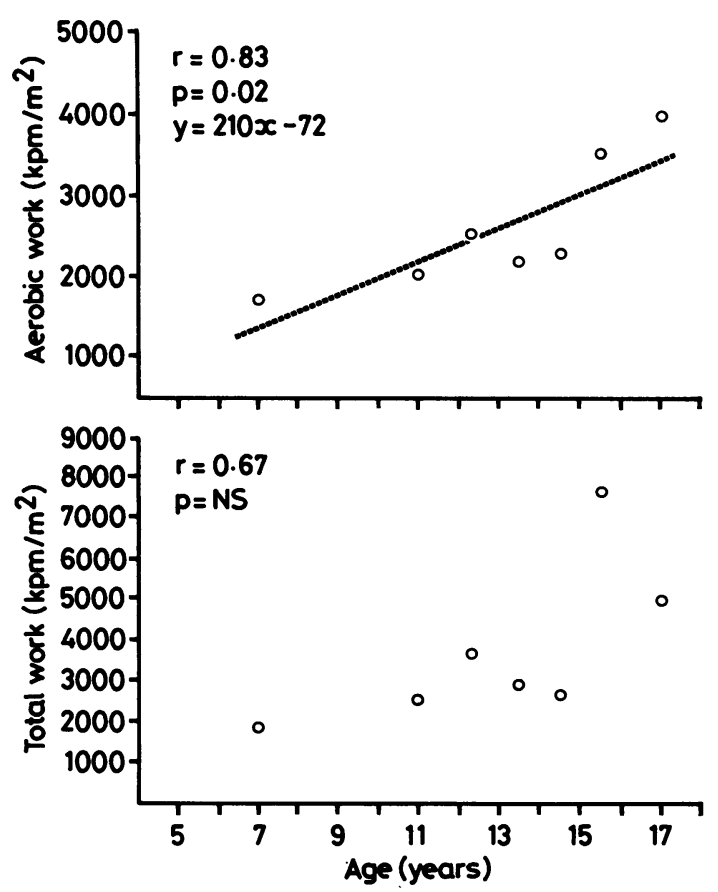

Fig. 1 Work performed on the bicycle ergometer by patient age. See text for explanation of aerobic work. $\mathrm{kpm} / \mathrm{m}^{2}$, kilopond metres per square metre. Conversion: traditional units to $S I-1 \mathrm{kpm} / \mathrm{m}^{2}=9.807 \mathrm{Y} / \mathrm{m}^{2}$.

21 children exercised for $2-4$ minutes $(3.3(0 \cdot 8) \mathrm{min})$ of their final exercise stage and had adequate radionuclide images for this last stage.

\section{STATISTICAL ANALYSIS}

Group values obtained at rest and during peak exercise are given as means and standard deviation. Group means were compared by one way analysis of variance followed by a Newman-Keuls multiple comparisons test. ${ }^{12}$ Correlations were assessed by linear regression analysis. A probability value of $p<0.05$ was regarded as being statistically significant.

\section{Results}

\section{EXERCISE PERFORMANCE}

Table 1 summarises some of the exercise performance results. All patients exercised beyond their anaerobic threshold as shown by the onset of tachypnoea in all patients ${ }^{13}$ In the subgroup of eight patients in whom lactic acid concentrations were measured they increased from $2.0(0.8) \mathrm{mg} / \mathrm{dl}$ $(0.22(0.09) \mathrm{mmol} / \mathrm{l})$ at rest to $5.6(1.5) \mathrm{mg} / \mathrm{dl}(0.62$ $(0.17) \mathrm{mmol} / \mathrm{l})$ after exercise. Lactic acid concentrations increased by from 1 to $5.5 \mathrm{mg} / \mathrm{dl}(0.11$ to
$0.61 \mathrm{mmol} / 1)$. Serum bicarbonate concentrations fell before the end of exercise in all seven patients in whom venous blood gases were monitored.

Heart rate always increased by at least 55 beats per minute and blood pressure increased by at least 20 $\mathrm{mm} \mathrm{Hg}$ (systolic).

We divided patients into three groups (group 1, 5-9 years; group 2, 10-14 years; group 3, 15-19 years) to determine the effect of age and sex on exercise variables.

Sex-There were $43 \%, 35 \%$, and $38 \%$ female patients in groups 1, 2, and 3 respectively. We found no significant difference between boys and girls at any age in the responses of heart rate or blood pressure to exercise. In age group 3, however, boys were able to exercise for a significantly longer period and perform a significantly greater amount of work $(\mathrm{p}<0.05)$ than girls.

Age-We found no significant difference between age groups 1 and 2 in the heart rate or blood pressure response to exercise. Age group 3, however, had a significantly greater heart rate increase (but not blood pressure increase) than did the younger patients. In addition, the older patients tended to exercise for longer, and perform more work per square metre of surface area. In boys the total workload per square metre correlated with age $(r=0.57$ $\mathrm{p}<0.05$ ), but there was no significant correlation between age and workload in girls.

Since total workload is in part dependent on effort and aerobic capacity we assessed the age dependence of the anaerobic threshold as well as the total workload in the subgroup in which venous blood gases were measured. Aerobic work was defined as the work per square metre achieved before there was an abrupt decrease in base deficit (anaerobic threshold). There was a very strong correlation between aerobic work and age $(r=0.83, p<0.05)$. In this subgroup, however, there was no significant correlation between total workload and age (see Fig. 1). Workload achieved in our three age groups was at least $1900(18 \cdot 6)$ (group 1), 2100(20.6) (group 2), and 2700 (26) (group 3) $\mathrm{kpm} / \mathrm{m}^{2}\left(\mathrm{~kJ} / \mathrm{m}^{2}\right)$ regardless of sex. The expected aerobic workload $\left(\mathrm{kpm} / \mathrm{m}^{2} ; \mathrm{kJ} / \mathrm{m}^{2}\right)$ is approximately 210 times the patient's age in years.

\section{RADIONUCLIDE VENTRICULOGRAPHY \\ Cardiac performance}

The ejection fractions of the left and right ventricles are shown in Fig. 2. Only one patient had a resting left ventricular ejection fraction of less than $50 \%$. In this patient, who was referred because of occasional extrasystoles, the left ventricular ejection fraction increased to $70 \%$ with exercise. Five patients had resting right ventricular ejection fractions of less than $40 \%$. Three of these patients were being 



Fig. 2 (a) Left and (b) right ventricular ejection fractions at rest and at peak exercise. Means (1SD) are given.

investigated for minor arrhythmias, one for chest pain, and one had had repair of an atrial septal defect. In all five patients the ejection fraction increased by at least 5\% (5 ejection fraction units) with exercise.

Table 2 summarises the responses of the right and left ventricles to the stress of exercise. Ejection fraction decreased by more than $5 \%$ (5 ejection fraction units) in only one patient. This patient had a history of supraventricular tachycardia. Her left ventricular ejection fraction decreased from $74 \%$ to $65 \%$ with exercise, whereas the right ventricular ejection frac-

Table 2 Ejection fraction changes with exercise (figures are numbers of patients)

\begin{tabular}{llll}
\hline & $\begin{array}{l}\text { Increase } \\
\text { by }>5 \%\end{array}$ & $\begin{array}{l}\text { Change } \\
\leqslant 5 \%\end{array}$ & $\begin{array}{l}\text { Decrease } \\
\text { by }>5 \%\end{array}$ \\
\hline Left ventricle & 22 & 9 & 1 \\
Right ventricle & 28 & 4 & 0 \\
\hline
\end{tabular}

tion increased from $45 \%$ to $62 \%$.

Nine patients had a change of less than $5 \%$ in their left ventricular ejection fraction. In eight of the nine patients their ejection fraction increased slightly (mean $+2 \cdot 4(0 \cdot 8) \%$ ) and in one patient it increased by $2 \%$. Six of these nine patients had a resting ejection fraction of more than $65 \%$. The remaining three patients had resting left ventricular ejection fractions of $62 \%, 55 \%$, and $51 \%$. The diagnosis at referral in these three patients were paroxysmal supraventricular tachycardia, postoperative atrial septal defect repair, and ventricular ectopy respectively.

Four patients had a change of less than $5 \%$ in right ventricular ejection fraction. The ejection fraction increased in all four patients (mean $+2(0.7) \%$ ). These patients had resting ejection fractions of $58 \%$, $52 \%, 52 \%$, and $50 \%$. They were referred with hyperlipidaema, paroxysmal supraventricular tachycardia (2), and chest pain respectively.

Cardiac index increased with exercise in all 

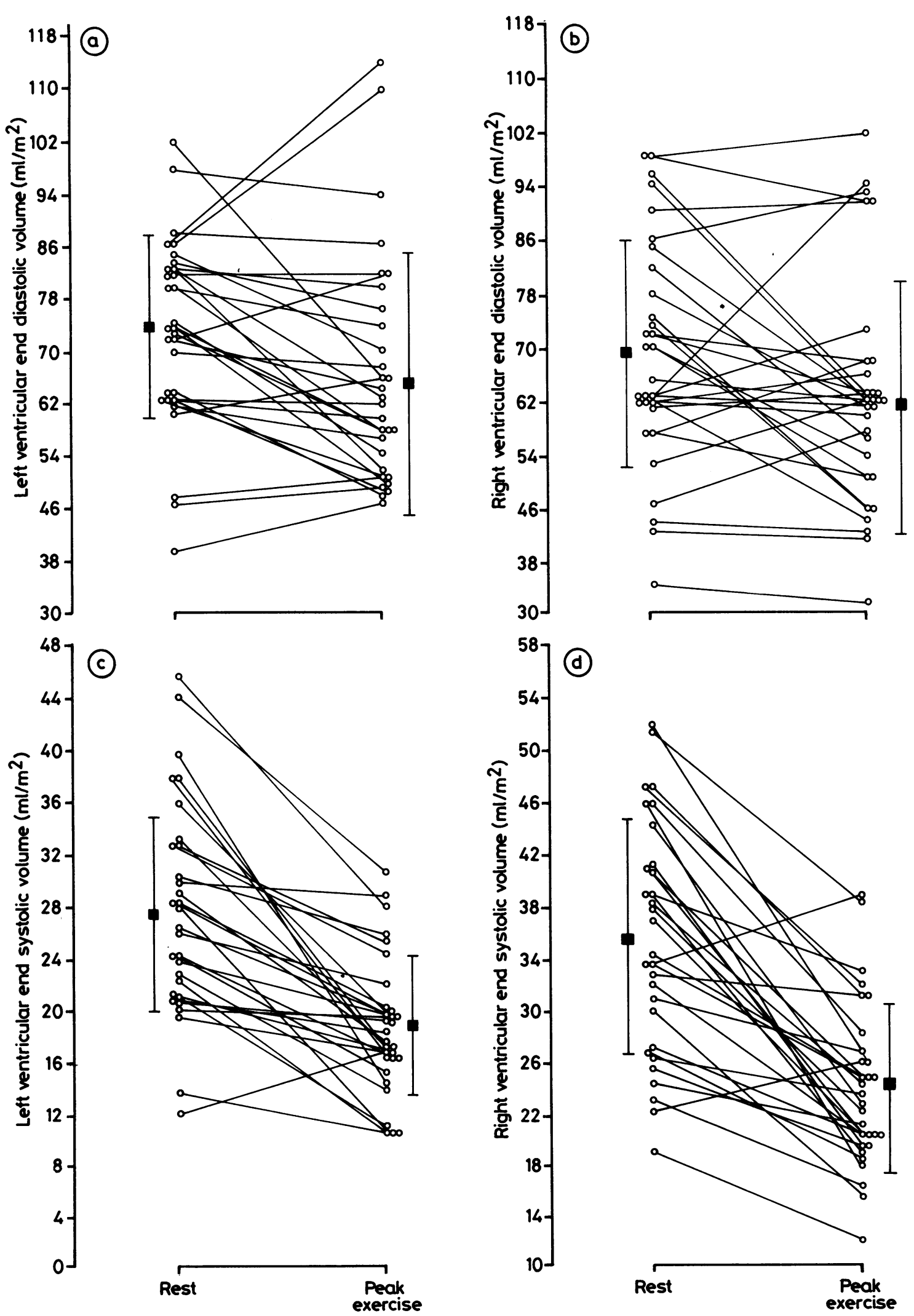

Fig. 3 (a) Left and (b) right ventricular end diastolic volumes and (c) left and (d) right ventricular end systolic volumes determined by a geometric technique at rest and at peak exercise. Means (1 SD) are shown. 
Table 3 Results of radionuclide ventriculography in 32 children without significant cardiovascular disease

\begin{tabular}{|c|c|c|c|c|}
\hline & \multicolumn{2}{|l|}{ Rest } & \multicolumn{2}{|l|}{ Exercise } \\
\hline & Lower limit & Upper limit & Lower limit & Upper limit \\
\hline $\begin{array}{l}\text { LV ejection fraction } \\
\text { RV ejection fraction } \\
\text { LV }: \text { RV end diastolic volume ratio (CT) } \\
\text { LV : RV end diastolic volume ratio (GEO) }\end{array}$ & $\begin{array}{l}0.50 \\
0 \cdot 35 \\
0 \cdot 90 \\
0 \cdot 70\end{array}$ & $\begin{array}{l}0.75 \\
0.65 \\
1.85 \\
1.50\end{array}$ & $\begin{array}{l}0.55 \\
0.50 \\
- \\
-\end{array}$ & $\begin{array}{l}0.85 \\
0.75 \\
-\end{array}$ \\
\hline
\end{tabular}

CT, method based on regional counts; GEO, method based on geometric volume determination; LV, left ventricle; $R V$, right ventricle.

patients $(+234(65) \%)$. Changes in cardiac index ranged from $+129 \%$ to $+448 \%$. Neither age nor total workload per square metre, however, correlated with change in cardiac index.

\section{Ventricular volumes}

Figure 3 shows the ventricular volumes at rest and with exercise. The responses of right and left ventricular end diastolic volumes to exercise were variable. Eight patients showed increases in left ventricular end diastolic volume with exercise, whereas the rest showed a decrease. Similarly, for the right ventricle, 10 patients showed an increase in end diastolic volume and the remaining patients showed a decrease. The mean (SD) change in left and right ventricular end diastolic volumes for the whole group was $-9 \cdot 8(19 \cdot 8) \%$ and $-8 \cdot 1(19 \cdot 8) \%$ respectively. The differences between the mean resting and mean peak exercise end diastolic volumes were not statistically significant.

The response of the end systolic volumes to exercise was more consistent than that of the end diastolic volumes (Figs. $3 \mathrm{c}$ and $3 \mathrm{~d}$ ). All but one patient showed a decrease in left ventricular end systolic volume with exercise. The mean (SD) change for the group was $-29(22) \%$. Similarly, right ventricular end systolic volumes increased with exercise in only two patients. The mean change in right ventricular end systolic volume with exercise was -30 (19) $\%$. The peak exercise end systolic volumes of both ventricles were significantly less than their resting end systolic volumes.

One patient in whom left ventricular end systolic volume increased with exercise also showed a $9 \%$ decrease in left ventricular ejection fraction. This patient had a history of supraventricular tachycardia but was otherwise normal. In two patients right ventricular end systolic volume increased with exercise. One of these patients (history of supraventricular tachycardia) had an increase in both left and right ventricular ejection fractions with exercise of $6 \%$ and $8 \%$ respectively. The remaining patient (postoperative atrial septal defect repair) showed an increase of only $4 \%$ and $2 \%$ for his left and right ventricles respectively.

We also assessed the ratio of the left ventricular end diastolic counts to right ventricular end diastolic counts. This volume assessment is relatively independent of geometric considerations. As assessed by this count based method the mean (SD) left ventricular to right ventricular end diastolic volume ratio was $1 \cdot 26(0.26)$ with a range of 0.85 to 1.84 . The volume ratio did not change significantly with exercise $(1 \cdot 28(0 \cdot 27)$; range $0.93-2 \cdot 16)$. A similar volume ratio was derived by geometric estimation of end diastolic volumes. At rest this geometric volume ratio was $1 \cdot 10(0 \cdot 22)$ (range $0 \cdot 70-1 \cdot 48$ ), and with exercise it was $1 \cdot 11(0 \cdot 27)$ (range $0 \cdot 79-1 \cdot 77$ ). The difference between the count based and geometric based volume ratios was not statistically significant.

Table 3 summarises what we consider to be normal radionuclide ventriculography findings in children, based on our results in this group of 32 patients without significant cardiovascular disease. The upper and lower limit numbers encompass the range of values seen in our patient group to the nearest 0.05 units.

\section{Discussion}

We have already discussed some of the technical considerations when supine exercise and radionuclide ventriculography is performed in children..$^{9-11}$ This technique seems to be safe and the results compare well with cineangiography in children with diverse types of cardiac disease. One potential drawback, however, of the multigated technique used here is that the peak exercise results are an average of cardiac performance for several minutes before the subject stops exercising. Thus, our results at peak exercise may differ slightly from those obtained by other methods which provide a more rapid determination of cardiac performance. The use of a first pass radionuclide technique would avoid this difficulty. ${ }^{14-16}$

The mean resting right and left ventricular ejection fractions in our study are lower than those usually found by cineangiography ${ }^{1718}$ or with a first pass radionuclide technique. ${ }^{14-16}$ This may be due to any one of several factors including: inherent differences between a rapid ejection fraction determination (cineangiography) and a time averaging 
technique (radionuclide ventriculography); a consistent small error in the correction for background activity; or overlap of atrial and ventricular activity at end systole.

Our results for blood pressure and heart rate response and total work resemble those for upright bicycle exercise in normal children ${ }^{19}$ and those for treadmill exercise in normal children. ${ }^{20}$ In common with these previous studies, we also found that exercise duration and total workload increase with age. In addition, we found that separate analysis of aerobic and anaerobic work by means of venous blood gases seemed to improve our assessment of working capacity by increasing the correlation between age and total workload.

Cardiac output in response to exercise has been measured in normal children by Cumming ${ }^{21}$ and by Lock et al. ${ }^{22}$ They found a mean increase in cardiac output of $187 \%$ and $258 \%$ respectively. These results resemble the increase of $234(65) \%$ in our study.

The ejection fraction response to exercise for both ventricles has been described in normal adults. ${ }^{23-25}$ In adults, as in our children, the ejection fraction for both ventricles usually increases by at least 5\% (5 ejection fraction units) with exercise. We found that a decrease in right or left ventricular ejection fraction of more than $5 \%$ is quite unusual in normal children (1 of 32) and we regard this as an abnormal response. Interpretation of an abnormal ejection fraction response, however, must be cautious because this measure of ventricular performance is influenced by preload, afterload, and contractility.

Relative changes in the end systolic and end diastolic volumes with exercise determine the ejection fraction response to exercise. We found that the right and left ventricular end systolic volumes usually decrease with exercise, whereas the response of the end diastolic volume is variable. Indeed we consider an increase in end systolic volume with exercise to be abnormal since this response is very unusual in normal children. End diastolic volume is more likely to increase during upright exercise. ${ }^{26}$

We conclude that exercise radionuclide ventriculography is an excellent technique for combined assessment of exercise capacity and evaluation of ventricular size and performance in children.

MDP was supported as a research fellow of the American Heart Association, Tennessee Affiliate.

\section{References}

1 Borow KM, Green LH, Castaneda AR, Keane JF. Left ventricular function after repair of tetralogy of Fallot and its relationship to age at surgery. Circulation 1980; 61: $1150-8$.

2 Hagler DJ, Ritter DG, Mair DD, et al. Right and left ventricular function after the Mustard procedure in transposition of the great arteries. Am $\mathcal{F}$ Cardiol 1979; 44: 276-83.

3 Fontan F, Deville C, Quaegebeur J, Ottenkamp J, Choussat A, Brom G. Repair of tricuspid atresia in 100 patients. I Thorac Cardiovasc Surg 1983; 85: 647-60.

4 Reduto LA, Berger HJ, Johnstone DE, et al. Radionuclide assessment of right and left ventricular exercise reserve after total correction of tetralogy of Fallot. $\mathrm{Am}$ f Cardiol 1980; 45: 1013-8.

5 Murphy JH, Barlai-Kovach MM, Mathews RA, et al. Rest and exercise right and left ventricular function late after the Mustard operation: assessment by radionuclide ventriculography. $A m \mathcal{F}$ Cardiol 1983; 51: 1520-6.

6 Parrish MD, Graham TP Jr, Bender HW, Jones JP, Patton J, Partain CL. Radionuclide angiographic evaluation of right and left ventricular function during exercise after repair of transposition of the great arteries. Circulation 1983; 67: 178-83.

7 Godfrey S. Exercise testing in children. London: WB Saunders, 1974: 66-101.

8 Alpert BS, Flood NL, Balfour IC, Strong WB. Automated blood pressure measurement during ergometer exercise in children. Cathet Cardiovasc Diagn 1982; 8: 525-33.

9 Parrish MD, Graham TP Jr, Born ML, Jones J. Radionuclide evaluation of right and left ventricular function in children: validation of methodology. Am $\mathcal{f}$ Cardiol 1982; 49: 1241-7.

10 Parrish MD, Graham TP Jr, Born ML, Jones TP, Boucek RJ Jr, Partain CL. Radionuclide ventriculography for assessment of absolute right and left ventricular volumes in children. Circulation 1982; 66: 811-9.

11 Parrish MD, Graham TP Jr, Born ML, et al. Radionuclide stroke count ratios for assessment of right and left ventricular volume overload in children. $\mathrm{Am}$ f $\mathrm{Car}$ diol 1983; 51: 261-4.

12 Snedecor GW, Cochran WG. Statistical methods. 7th ed. Ames: Iowa State University Press, 1980: 235-50.

13 Wasserman K. Dyspnea on exertion: is it the heart or the lungs? $\mathcal{F} A M A$ 1982; 248: 2039-43.

14 Kurtz D, Ahnberg DS, Freed M, Lafarge CG, Treves S. Quantitative radionuclide angiocardiography determination of left ventricular ejection fraction in children. Br Heart f 1976; 38: 966-73.

15 Folland ED, Hamilton GW, Larson SM, Kennedy JW, Williams DL, Ritchie JL. The radionuclide ejection fraction: a comparison of three radionuclide techniques with contrast angiography. $f \mathrm{Nucl}$ Med 1977; 18: 1159-66.

16 Berger HJ, Johnstone DE, Sands JM, Gottschalk A, Zaret BL. Response of right ventricular ejection fraction to upright bicycle exercise in coronary artery disease. Circulation 1979; 60: 1292-300.

17 Graham TP Jr, Jarmakani JM, Canent RV Jr, Morrow $M N$. Left heart volume estimation in infancy and childhood: re-evaluation of methodology and normal values. 
Circulation 1971; 43: 895-904.

18 Graham TP Jr, Jarmakani JM, Atwood GF, Canent RV Jr. Right ventricular volume determinations in children. Circulation 1973; 47: 144-53.

19 James FW, Kaplan S, Glueck CJ, Tsay JY, Knight MJS, Sarwar CJ. Responses of normal children and young adults to controlled bicycle exercise. Circulation 1980; 61: 902-12.

20 Riopel DA, Taylor AB, Hohn AR. Blood pressure, heart rate, pressure-rate product and electrocardiographic changes in healthy children during treadmill exercise. Am f Cardiol 1979; 44: 697-704.

21 Cumming GR. Hemodynamics of supine bicycle exercise in "normal" children. Am Heart $\mathcal{f}$ 1977; 93: 617-22.

22 Lock JE, Einzig S, Moller JH. Hemodynamic responses to exercise in normal children. Am $\mathcal{f}$ Cardiol 1978; 41: 1278-84.
23 Pfisterer ME, Ricci DR, Schuler G, et al. Validity of left ventricular ejection fractions measured at rest and peak exercise by equilibrium radionuclide angiography using short acquisition times. $\mathcal{f}$ Nucl Med 1979; 20: 484-90.

24 Upton MT, Rerych SK, Newman GE, Bounous EP Jr, Jones RH. The reproducibility of radionuclide angiographic measurements of left ventricular function in normal subjects at rest and during exercise. Circulation 1980; 62: 126-32.

25 Maddahi J, Berman DS, Matsuoka DT, Waxman AD, Forrester JS, Swan HJC. Right ventricular ejection fraction during exercise in normal subjects and in coronary artery disease patients: assessment by multiplegated equilibrium scintigraphy. Circulation 1980; 62: . 133-40.

26 Slutsky R. Response of the left ventricle to stress: effects of exercise, atrial pacing, afterload stress and drugs. Am F Cardiol 1981; 47: 357-64. 